\title{
Vitamin K-Dependent Carboxylase Activity in Fetal Rat Lung: Developmental Effects of Dexamethasone and Triiodothyronine ${ }^{1}$
}

\author{
KEITH J. GALLAHER, D. EUGENE RANNELS, AND STEPHEN R. RANNELS \\ Departments of Pediatrics, Division of Newborn Medicine [K.J.G.], and Physiology [D.E.R., S.R.R.], The \\ Pennsylvania State University, The Milton S. Hershey Medical Center, Hershey, PA 17033
}

\begin{abstract}
Dexamethasone (Dex) and triiodothyronine $\left(T_{3}\right)$ were administered to pregnant rats during late gestation to evaluate potential developmental effects on fetal lung vitamin K-dependent carboxylation. Maternal rats were injected on the $2 \mathrm{~d}$ before study with Dex $(0.2 \mathrm{mg} / \mathrm{kg}$ intraperitoneally), with $T_{3}(0.7,3.5$, or $7 \mathrm{mg} / \mathrm{kg}$ intramuscularly), or with a combination of both hormones. Fetal lung microsomes were prepared at 18, 19, and $20 \mathrm{~d}$ of gestation, and carboxylase activity was assessed by measuring the incorporation of ${ }^{14} \mathrm{CO}_{2}$ into a synthetic pentapeptide substrate. Dex alone resulted in a small but consistent increase in activity in all three gestational ages. $T_{3}$ alone increased activity approximately $85 \%$ at $20 \mathrm{~d}$ of gestation. Treatment with a combination of Dex and $\mathrm{T}_{3}$ caused a $60 \%$ increase in vitamin K-dependent carboxylation at each gestational age. Decreased lung growth was noted with combination hormone treatment in all rats studied at 19 and $20 \mathrm{~d}$ of gestation. Lung growth expressed as lung wt/ body wt was more sensitive to the effects of Dex plus $T_{3}$ than was carboxylase activity. Decreased lung wt/body wt (decreased $25 \%$ ) was noted with Dex plus $\mathrm{T}_{3}(0.7 \mathrm{mg} / \mathrm{kg})$; however, no induction of carboxylase enzyme activity was evident at this dose. This study demonstrates that vitamin $\mathrm{K}$-dependent carboxylase activity in fetal rat lung can be induced by the exogenous administration of Dex and $T_{3}$ to pregnant rats. Fetal lung microsomes contain multiple endogenous substrates for the vitamin K-dependent carboxylase enzyme. These hormones play a significant developmental role not only in protein biosynthesis, but in posttranslational processing as well. The more general effects of hormone treatment on lung growth can be distinguished from a relatively specific effect on lung vitamin Kdependent carboxylase activity by a difference in sensitivity of these responses to hormone treatment. (Pediatr Res 25: $530-534,1989$ )
\end{abstract}

\section{Abbreviations}

SP-A, high molecular weight surfactant protein

Gla, $\gamma$-carboxyglutamate

Dex, dexamethasone

$T_{3}$, triiodothyronine

Received August 8, 1988; accepted January 3, 1989.

Correspondence and reprint requests Keith J. Gallaher, M.D., Department of Pediatrics, Division of Newborn Medicine, The Pennsylvania State University, The Milton S. Hershey Medical Center, Hershey, PA 17033

Supported by a Grant-in-Aid from The American Heart Association with funds contributed in part by the AHA Pennsylvania Affiliate, and by HL-20344 from the National Heart, Lung and Blood Institute of the National Institutes of Health. K.J.G. is the recipient of National Research Service Award HL07589. S.R.R. is an Established Investigator of The American Heart Association.

Presented in part at the Annual Meeting of the Society for Pediatric Research, Washington, DC, May 1988.

\author{
$\mathrm{K}_{1} \mathrm{H}_{2}$, reduced vitamin $\mathrm{K}$ \\ IP, intraperitoneal \\ IM, intramuscular
}

Pulmonary surfactant is a complex mixture of lipids, proteins, and carbohydrates that facilitates the maintainance of alveolar stability at low lung vol (1). Surface active characteristics of surfactant both in vivo and in vitro are dependent on complex interactions between the protein and lipid components (2). Surfactant proteins are specific to the lung and are subdivided into at least three groups: a higher mol wt $(28-40 \mathrm{kD})$ acidic group, and two lower mol wt lipophilic groups (2). The lower mol wt proteins are intimately associated with the lipid components of surfactant and are required for their in vivo and in vitro activity $(3,4)$. The higher mol wt proteins (SP-A), by contrast, further modify the surface characteristics of surfactant (3) and appear to be involved in the formation of the complex, three-dimensional, extracellular form of surfactant known as tubular myelin (5). SPA has also been implicated as having a regulatory role in surfactant lipid turnover (6) and may be involved in the immunologic defense of the alveolus (7)

The interactions of SP-A with surfactant lipids are $\mathrm{Ca}^{++} \mathrm{de}-$ pendent (8). We have recently described a posttranslational modification of rat lung SP-A that provides a structural basis for this interaction (9), namely, that glutamic acid residues of the protein are carboxylated in a vitamin K-dependent pathway to yield Gla. This posttranslational modification is analagous to that of the well-characterized blood coagulation factors. In the clotting system, the normal interactions of the vitamin K-dependent factors with lipids in the coagulation cascade are dependent upon $\gamma$-carboxylation, in which the Gla residues of proteins confer the capacity for calcium-dependent interactions with phospholipids. Other than the vitamin K-dependent clotting factors, SP-A is one of only a few $\gamma$-carboxylated proteins for which specific in vivo functions have been identified (10).

Development of the vitamin-K dependent carboxylase system in fetal rat lung can be distinguished clearly from the more completely characterized system of the liver. We have previously shown that fetal rat lung vitamin K-dependent carboxylase activity increases to adult levels during late gestation (d 18, 19), in contrast to liver carboxylase activity, which continues to increase until adulthood (9).

Both the protein and the lipid components of pulmonary surfactant are known to appear during late gestation (d 18-21) in the fetal rat $(11,12)$. The enzymatic capability for surfactant protein carboxylation therefore is available at the time when SPA appears in lung microsomes. This normal, late-gestational maturation of the surfactant system requires both adrenal glu- 
cocorticoids and thyroid hormones. When administered exogenously, these hormones have additive stimulatory effects of surfactant lipid synthesis (13); however, the role of $\mathrm{T}_{3}$ in SP-A production is unclear $(14,15)$.

In this present study, we have investigated whether the administration of exogenous glucocorticoids and/or triiodothyronine $\left(\mathrm{T}_{3}\right)$ to pregnant rats would induce fetal lung carboxylase activity. We have studied stimulation of vitamin K-dependent carboxylation by these hormones throughout that range of gestational ages where dramatic changes in the maturation of the surfactant system are known to occur.

\section{MATERIALS AND METHODS}

Timed-pregnant female Sprague-Dawley rats are obtained from Charles River Laboratories. Dex $(0.2 \mathrm{mg} / \mathrm{kg}$, diluted in $0.9 \% \mathrm{NaCl}$ ) is given IP in the morning of the $2 \mathrm{~d}$ before the study. Triiodothyronine $(0.7,3.5$, or $7 \mathrm{mg} / \mathrm{kg}$ in $0.45 \% \mathrm{NaOH} /$ $0.45 \% \mathrm{NaCl}$ ) is given IM on the same schedule. The $7-\mathrm{mg} / \mathrm{kg}$ dosage has previously been shown by Gross et al. (13) to give maximal stimulation of choline incorporation into phosphatidylcholine by fetal lung, without a change in endogenous corticosteroid levels. Appropriate placebo controls are used.

Fetuses are removed from ether-anesthetized females, then decapitated, bled, and promptly cooled to $4^{\circ} \mathrm{C}$ in isotonic saline before lung or liver dissection. Tissues are homogenized in $25-$ $\mathrm{mM}$ imidazole buffer ( $\mathrm{pH} 7.2$ ) with $250-\mathrm{mM}$ sucrose (SI buffer), using 10 strokes with a Potter-Elvehjem homogenizer (Thomas Scientific, Swedesboro, NJ). A microsomal pellet is obtained after centrifugation of the homogenate at $10000 \times g(15 \mathrm{~min})$ and further centrifugation of the resulting supernatent at 100000 $\times g$ for $60 \mathrm{~min}$. Microsomes are resuspended and solubilized by homogenization into $25-\mathrm{mM}$ imidazole buffer ( $\mathrm{pH} 7.2$ ) with $0.5 \%$ (wt/vol) CHAPS (3-[(3-cholamidopropyl) dimethyl ammonio]-1-propane sulfonate), and aliquots are stored at $-75^{\circ} \mathrm{C}$ for subsequent assay (within 2-3 d).

Vitamin-K dependent carboxylase activity is estimated in microsomal preparations by the addition of chemically reduced vitamin- $\mathrm{K}\left(\mathrm{K}_{1} \mathrm{H}_{2}\right)$ and is based on the incorporation of ${ }^{14} \mathrm{CO}_{2}$ into an acid-soluble synthetic pentapeptide (Phe-Leu-Glu-GluLeu; Vega Corp., Tucson, AZ) after precipitation of microsomal proteins with cold trichloroacetic acid (16). Specifically, resuspended lung microsomes are incubated at $25^{\circ} \mathrm{C}$ for $30 \mathrm{~min}$ in a $240-\mu \mathrm{L}$ reaction mixture containing $1-\mathrm{mM} \mathrm{MnCl}_{2}, 5.2-\mathrm{mM}$ dithiothreitol, 2-mM pentapeptide, $100 \mu \mathrm{g} / \mathrm{mL}$ vitamin $\mathrm{K}_{1} \mathrm{H}_{2}$, and $20 \mu \mathrm{Ci} / \mathrm{mL} \mathrm{NaH}{ }^{14} \mathrm{CO}_{3}$. The reaction is stopped by adding $1 \mathrm{~mL}$ of cold trichloroacetic acid, and unbound ${ }^{14} \mathrm{CO}_{2}$ is removed by bubbling $\mathrm{CO}_{2}$ gas through the acid soluble supernatant before scintillation counting in ACS II (Amersham Corp., Arlington Heights, IL). Incorporation of isotope into peptide is linear over at least $30 \mathrm{~min}$ and is directly related to the amount of microsomal protein (data not shown) over at least a 4-fold range of dilution down to $120 \mu \mathrm{g}$ protein/assay. Endogenous proteins are carboxylated in a similar reaction mixture with no synthetic peptide present, this mixture is then dialyzed against $0.1-\mathrm{M}$ ammonium bicarbonate buffer and lyophilized in preparation for subsequent SDS-PAGE (9).

Specific proteins are identified by $12 \%$ SDS-PAGE using a Mini-Protean II slab gel apparatus (Bio-Rad Laboratories, Richmond, CA). Gels are stained with Coomassie Brilliant Blue R250 and relative mol wt are determined using protein standards (Bio-Rad), or their ${ }^{14} \mathrm{C}$-methylated derivatives (Amersham). Gels selected for autoradiography are fixed overnight in $40 \%$ methanol/7\% acetic acid (vol/vol) and then treated with $\mathrm{En}^{3} \mathrm{Hance}$ (New England Nuclear Products, Boston, MA) for 1 h before they are dried overnight. The dried gels are exposed to Kodak X-Omat XAR-5 film (Eastman Kodak Co., Rochester, NY) at $-75^{\circ} \mathrm{C}$ for $1 \mathrm{mo}$

Specific SP-A IgG is prepared as previously described (9). Briefly, purified surfactant obtained by lavage of 12 rats is suspended in distilled water to give $0.5 \mathrm{~mL}$, which is combined with an equal vol of Freund's complete adjuvant and injected at multiple intradermal sites into New Zealand white rabbits. Rabbits are given subcutaneous booster injections of $0.25 \mathrm{~mL}$ of the same surfactant preparation. Blood is drawn from an ear vein and the serum is stored at $-20^{\circ} \mathrm{C}$. IgG is purified by ammonium sulfate fractionation and DEAE-cellulose chromotagraphy as described by Fahey (17). Antibodies against serum protein contaminants of the surfactant preparation are removed from the IgG fraction by immunoaffinity chromatography, using a resin prepared with dialyzed rat serum and activated $\mathrm{CH}$-Sepharose 4B (Pharmacia Fine Chemicals, Uppsala, Sweden). For immunoblots, proteins are transferred from SDS-PAGE gels to nitrocellulose membranes using a Bio-Rad Mini Trans-Blot cell. Membranes treated in 50-mM Tris buffer, $\mathrm{pH} 7.4$, with $0.1-\mathrm{M}$ $\mathrm{NaCl}$ and $5 \%(\mathrm{wt} / \mathrm{vol}$ ) nonfat dry milk are incubated with specific antibody overnight at $4^{\circ} \mathrm{C}$. Immunoreactive protein bands are visualized after reaction with horseradish peroxidase-conjugated goat antirabbit IgG.

Total protein concentrations are determined using a modified Lowry assay (18) with BSA standards.

Radiochemicals are purchased from New England Nuclear; DEAE-Sephacel and H-Sepharose 4B, from Pharmacia; and all other biochemicals from Sigma Chemical Co. (St. Louis, MO) Dex sodium phosphate $(4 \mathrm{mg} / \mathrm{mL})$ is obtained from Lypho Med, Inc. (Melrose Park, IL), and triiodothyronine from Sigma.

For enzyme studies, lungs from each litter are pooled and homogenized. Microsomal fractions from each litter are analyzed in duplicate in the presence of $\mathrm{K}_{1} \mathrm{H}_{2}$ and compared against a blank (no vitamin) to give one value. Each treatment group consists of three-five litters. Hormone effects are assessed at only one gestational age on a given $\mathrm{d}$ and contrasted with parallel placebo controls. For the time-course data, breedings are coordinated such that all three gestational ages are studied simultaneously. Results are analyzed for statistical significance using ANOVA and Student's $t$ test.

\section{RESULTS}

$\gamma$-carboxylation of endogenous SP-A is detectable in microsomal preparations of fetal rat lung. A representative fluorogram of 20-d fetal lung microsomes radiolabeled with ${ }^{14} \mathrm{CO}_{2}$ in the presence of reduced vitamin $\mathrm{K}$ and separated by SDS-PAGE is shown in Figure 1, Lane $A$. Lane $B$ represents an immunoblot of a similar preparation using SP-A-specific IgG. Two immunoreactive bands, at 36000 and $31000 \mathrm{~mol} \mathrm{wt}$, are shown. The radiolabeled protein of higher mol wt was previously determined to be SP-A in adult type II pneumocytes by autoradiography of the actual immunoblot (9).

In vitro vitamin $\mathrm{K}$-dependent carboxylation of endogenous fetal lung proteins suggests a physiologic role for this posttranslational modification. To characterize the developmental regulation of the carboxylase system, a pentapeptide substrate was used to quantitate the enzyme activity in microsomes isolated from fetal lungs at several gestational ages. Several treatment protocols were designed whereby pregnant rats were injected with Dex and/or $T_{3}$ for $48 \mathrm{~h}$ before tissue isolation. Dex alone (treatment for the $2 \mathrm{~d}$ before study) resulted in a small but consistent increase in vitamin $\mathrm{K}$-dependent carboxylase activity; however, this $25 \%$ effect never reached statistical significance in numerous studies (Fig. 2). Coadministration of Dex and $\mathrm{T}_{3}$ are known to result in an additive stimulation of surfactant lipid synthesis in developing lung (13); however, opposite effects have been described on other indicators of fetal lung maturation, including the development of the antioxidant system (19). In the present studies, lung carboxylase activity increased $60 \%$ at all three gestational ages studied when a combination of Dex and $\mathrm{T}_{3}$ was administered to the pregnant females for $2 \mathrm{~d}$ (Fig. 2). Administration of $\mathrm{T}_{3}$ alone on gestational d 18 and 19 resulted in a $77 \%$ increase in carboxylase activity, as compared to the 


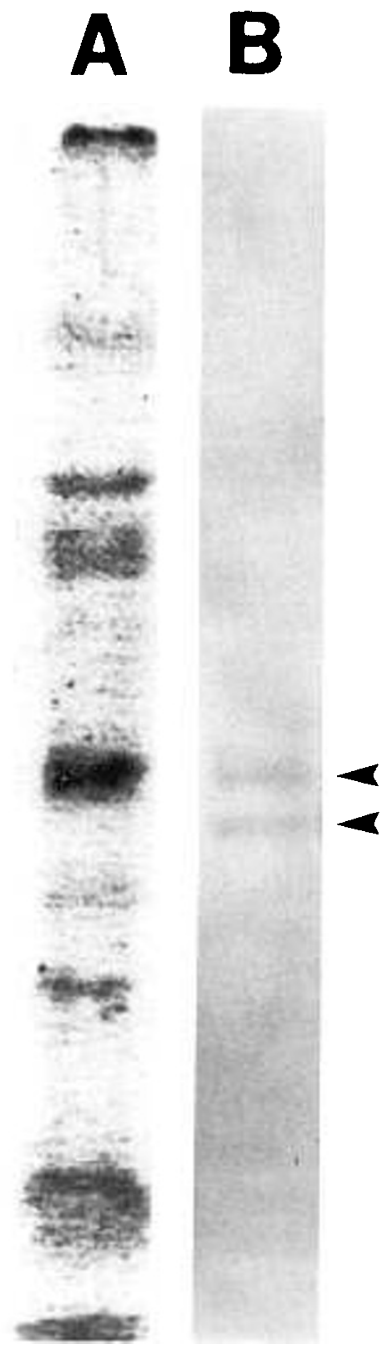

Fig. 1. Microsomal subfractions of $20 \mathrm{~d}$ fetal rat lung were separated by $12 \%$ SDS-PAGE. Lane $A$ represents a fluorogram of proteins radiolabeled in vitro with ${ }^{14} \mathrm{CO}_{2}$ in the presence of $\mathrm{K}_{1} \mathrm{H}_{2}$. Lane $B$ is an immunoblot of a similar sample using anti-SPA IgG. Two immunoreactive bands ( 36000 and $31000 \mathrm{~mol}$ wt) are identified (arrowheads), and the higher mol wt band ( $36 \mathrm{kD}$ ) is gamma carboxylated.

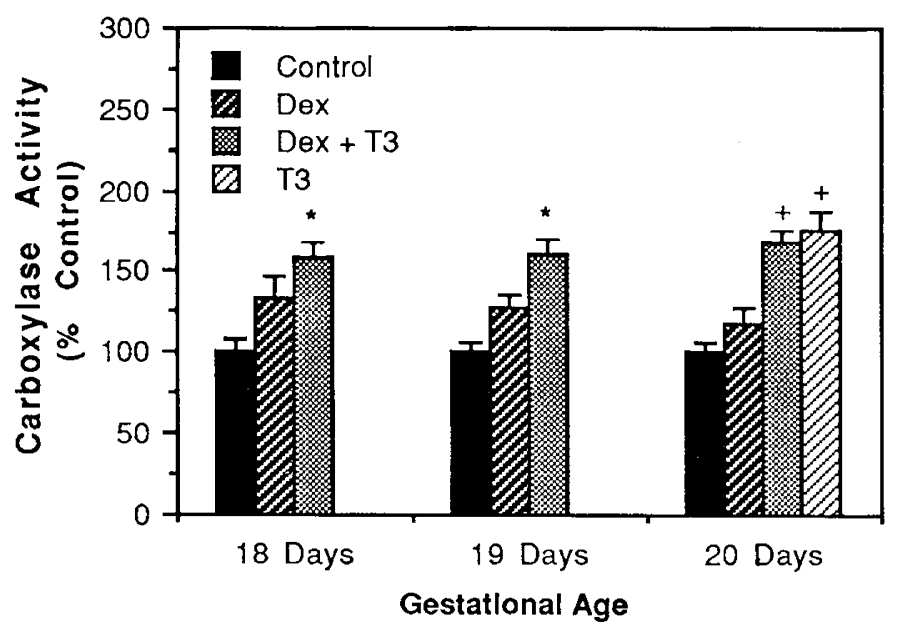

Fig. 2. Vitamin K-dependent carboxylase activity was assayed in fetal lung microsomes after maternal treatment with hormones on the $2 \mathrm{~d}$ before study. Results are expressed as a percentage of placebo control \pm SEM, $(n=4-7$ litters $)$ and represent the incorporation of ${ }^{14} \mathrm{CO}_{2}$ into synthetic pentapeptide substrate in the presence of $\mathrm{K}_{1} \mathrm{H}_{2}\left({ }^{*} p \leq 0.02 v \mathrm{v}\right.$. control and $+p<0.02 v s$. control and Dex). control group. (Fig. 2). Hormonal stimulation did not abolish the gestational age associated increase in carboxylase activity which had been observed previously (data not shown) (9).

Lung wt normally increased nearly 4 -fold between 18 and 20 $\mathrm{d}$ of gestation (Table 1). Decreased lung growth was noted with combination hormone treatment in rats studied at 19 and $20 \mathrm{~d}$ of gestation, but not when the hormones were administered at $d$ 16 and 17, (study d 18). At the earlier gestational ages, rapid increases in lung wt have not yet begun. This effect appeared to be organ specific, as body wt in general was not affected (not shown). Lower doses of $T_{3}$ in conjunction with Dex were tested at gestational d 20 to separate general effects of $T_{3}$ on lung growth from the stimulatory effect on carboxylase activity. These results showed a preferential decrease in lung wt, as demonstrated by the lower lung wt to body wt ratio in the treatment groups relative to the placebo controls (Dex with no $\mathrm{T}_{3}$ ) (Fig. 3). This effect was noted at the lower dose of $T_{3}(0.7 \mathrm{mg} / \mathrm{kg})$ and was quantitatively similar to that observed with a dose of $3.5 \mathrm{mg} / \mathrm{kg}$. No induction of carboxylase enzyme activity was measured, however, at the lower dose of $\mathrm{T}_{3}$. At $3.5 \mathrm{mg} / \mathrm{kg} \mathrm{T}$, a minimal additional effect on lung wt/body wt, along with a $60 \%$ increase in carboxylase activity was evident. This result is qualitatively similar to the increase at the $7-\mathrm{mg} / \mathrm{kg} \mathrm{T}_{3}$ dosage (Fig. 2).

\section{DISCUSSION}

Vitamin K-dependent carboxylase activity was first characterized in microsomes from adult rat lung by Bell (16) in 1980 , when increases in enzyme activity were noted with vitamin $K$ deficiency and with warfarin treatment. Until our recent investigations, however, none of the substrates for the lung carboxylase enzyme had been described; we examined vitamin K-dependent carboxylase in fetal lung and in type II cells from adult rats, and found that SP-A and prothrombin are two of the endogenous substrates in the adult tissue $(9,20)$. The studies reported here are the first to address the role of hormones in regulation of fetal lung carboxylase activity and to initiate characterization of carboxylase substrates in developing lungs.

Lung vitamin K-dependent carboxylase activity is stimulated by $\operatorname{Dex}, \mathrm{T}_{3}$, and combinations of both hormones during late gestation in the fetal rat. The effect of combination hormone treatment was similar to that of $T_{3}$ alone. We have studied the induction of carboxylase activity by these hormones in fetal lung because of their known stimulatory effects on other key enzymes involved in lung maturation and surfactant production (2). In other systems involving Gla-containing proteins, similar effects on carboxylation by relevant hormones have been described. For example, serum bone Gla protein levels are increased by injection of $1,25(\mathrm{OH})_{2} \mathrm{D}_{3}(21)$; the synthesis of kidney Gla protein is stimulated by parathyroid hormone and by $1,25(\mathrm{OH})_{2} \mathrm{D}_{3}(22)$. In the latter case, both carboxylase enzyme activity and substrate levels were elevated by hormone treatment.

It is not clear whether the stimulatory effect of hormone treatment on lung carboxylase activity is a direct effect of the

Table 1. Effects of maternal hormone treatment on fetal lung $w t^{*}$

\begin{tabular}{lccc}
\hline & \multicolumn{3}{c}{ Fetal lung wt (mg/lung) $\dagger$} \\
\cline { 2 - 4 } & $18 \mathrm{~d}$ & \multicolumn{1}{c}{$19 \mathrm{~d}$} & $20 \mathrm{~d}$ \\
\hline Control & $16.1 \pm 0.8$ & $40.7 \pm 1.9$ & $68.5 \pm 3.1$ \\
Dex & $15.9 \pm 1.2$ & $34.0 \pm 0.6 \ddagger$ & $64.3 \pm 1.6$ \\
Dex $+\mathrm{T} 3$ & $16.4 \pm 0.8$ & $29.3 \pm 2.6 \S$ & $52.6 \pm 3.4 \S$ \\
\hline
\end{tabular}

* Lungs were removed from fetuses en bloc and dissected free from major airways. Tissues from each litter were combined and weighed, and the total was divided by the number of fetuses in the litter.

$\dagger$ Mean \pm SEM for four-five litters.

$\$ p \leq 0.02$ vs. control.

$\S p \leq 0.01$ vs. control. 


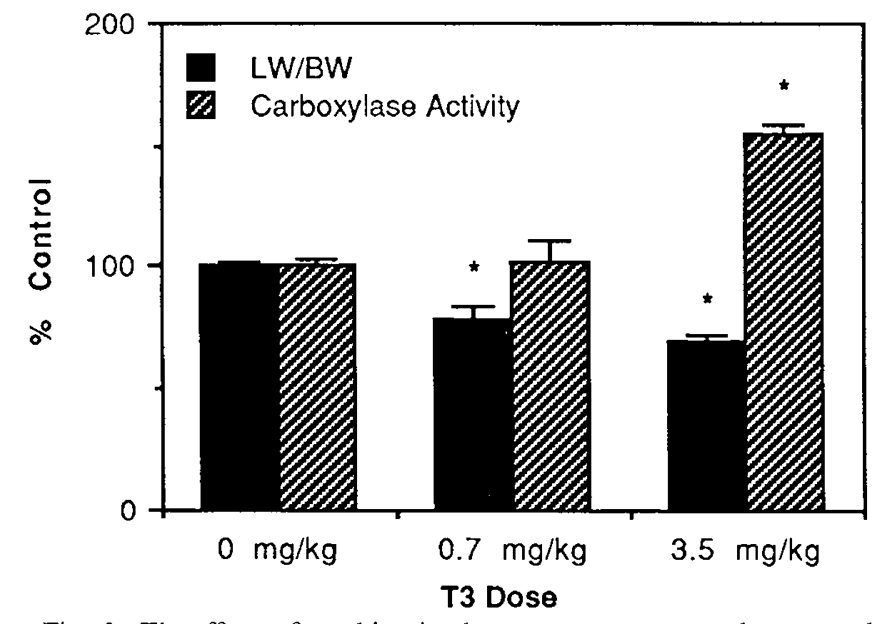

Fig. 3. The effects of combination hormone treatment on lung growth and carboxylase activity was assessed at $20 \mathrm{~d}$ of gestation using Dex and the doses of $\mathrm{T}_{3}$ indicated. $\left(n=4 ;{ }^{*} p \leq 0.001\right.$ relative to Dex alone).

hormone on carboxylase synthesis or its activity, or whether it represents an indirect effect which follows induction of some major substrate (e.g. SP-A). The observation that the relative increase in enzyme activity slightly precedes the increase in the amount of immunologically detectable microsomal SP-A (not shown) argues against the latter explanation. This observation is consistent with the findings of Ballard et al. (14), who showed that $T_{3}$ (alone or with Dex) did not lead to increases in either SP-A or its mRNA in fetal lung tissue. It is possible, however, that the amount of SP-A in the microsomal fraction represents only a portion of the carboxylated or carboxylatable substrate pool and, therefore, may be misleading as an assessment of substrate availability. There are multiple additional substrates of the vitamin K-dependent carboxylase enzyme which can be detected in fetal lung microsomes (Fig. 1). Though SP-A appears to be a major carboxylated product, it is possible that these alternative substrates may be increased by hormone treatment and that they could serve to induce enzyme activity to the level observed. Because in these studies whole lung microsomes were derived from multiple cell types, some of the activity changes may be related to different effects on multiple cell populations and/or substrates.

The possibility of direct hormonal stimulation of the carboxylase enzyme is supported by the finding of similar relative activities between gestational ages, but increased absolute activity with hormone treatment. Again, it is as yet not clear which cell type is most affected. It is likely, however, that much of the activity measured in fetal tissue reflects type II cell metabolism. We have previously shown that microsomes isolated from type II pneumocytes, but not lung macrophages, actively carboxylate both endogenous and exogenous substrates (22). The effect of hormone treatment on lung growth in the present studies, however, suggests the possibility of more widespread effects. $T_{3}$ administration in these studies is clearly associated with increases in carboxylase activity, yet this hormone is generally thought to have less specific effects on the type II cell than does Dex. It is likely therefore that some of the increase in activity is due to effects on other cell types. We have measured significant vitamin K-dependent carboxylase activity in microsomes from fetal lung fibroblasts (not shown), but fibroblast activity was below that observed in type II cells isolated from the same lungs at day 19 of gestation.

The observation that the $36-\mathrm{kD}$ SP-A polypeptide is the only carboxylated SP-A band detectable on fluorograms of fetal whole lung microsomes, whereas labeling of both the 31- and 36-kD polypeptides was observed in adult type II cell microsomes (9), suggests several possibilities. SP-A is a group of protein isoforms which differ by their degrees of glycosylation (2). It is possible that the highly glycosylated protein is a better substrate for the carboxylase than is the less glycosylated form $(31 \mathrm{kD})$. Anti-SPA immunoblots of both fetal lung and adult type II cell microsomes show similar relative amounts of SP-A in polypeptides of both mol wt, whereas, in these two tissues in vitro carboxylation of the larger polypeptide predominates. By contrast, the in vitro labeling of both polypeptide bands by the carboxylase enzyme in microsomes prepared from adult type II cells may reflect increased enzyme activity in that tissue relative to fetal whole lung microsomes. We have no evidence to suggest ${ }^{14} \mathrm{CO}_{2}$ incorporation into the $28000 \mathrm{~mol}$ wt band, which is reported to be the primary translation product of SP-A (23). This observation suggests that glycosylation precedes and may serve as a signal for subsequent carboxylation. This sequence of posttranslational modification is consistent with findings in the liver carboxylase system, where it is known that glycosylation of newly synthesized proteins occurs before carboxylation (10).

In summary, the present study identifies a role for glucocorticoids and thyroid hormone in the developmental regulation of vitamin K-dependent carboxylase in the lung. The more general effects of hormone treatment on lung growth could be distinguished from a relatively specific effect on lung vitamin Kdependent carboxylase activity by a difference in sensitivity of the two responses to hormone treatment. These findings suggest that vitamin $\mathrm{K}$-dependent carboxylation plays a significant role in the post-translational processing of lung proteins. The functional role of this modification and the identity of the multiple endogenous substrates remain to be elucidated.

Acknowledgments. The authors thank Dr. Reidar Wallin for valuable instruction, Dr. Ilene Sosenko for helpful advice, Dr. Nicholas Nelson for review of the manuscript, and Nancy Campbell for preparation of the manuscript.

\section{REFERENCES}

1. Jobe A, Ikegami M 1987 Surfactant for the treatment of respiratory distress syndrome. Am Rev Respir Dis 136:1256-1275

2. Wright RR, Clements JA 1987 Metabolism and turnover of lung surfactant. Am Rev Respir Dis 135:426-444

3. Hawgood S, Benson BJ, Schilling J, Damm D, Clements JA, White RT 1987 Nucleotide and amino acid sequences of pulmonary surfactant protein SP 18 and evidence for cooperation between SP 18 and SP 28-36 in surfactant lipid adsorption. Proc Natl Acad Sci USA 84:66-70

4. Whitsett JA, Ohning BL, Ross G, Meuth J, Weaver T, Holm BA. Shapiro DL. Notter RH 1986 Hydrophobic surfactant-associated protein in whole lung surfactant and its importance for biophysical activity in lung surfactant extracts used for replacement therapy. Pediatr Res 20:460-467

5. Williams MC, Benson BJ 1981 Immunocytochemical localization and identification of the major surfactant protein in adult rat lung. $J$ Histochem Cytochem 29:291-305

6. Dobbs LG, Wright JR, Hawgood S, Gonzalez R, Verstrom K, Nellenbogen J 1987 Pulmonary surfactant and its components inhibit secretion of phosphatidyl choline from cultured rat alveolar type II cells. Proc Natl Acad Sci USA 84:1010-1014

7. Hoffman RM, Claypool WD, Katyal SL. Singh G, Rogers RM, Dauber JH 1987 Augmentation of rat alveolar macrophage migration by surfactant protein. Am Rev Respir Dis 135:1358-1362

8. Hawgood S, Benson BJ, Hamilton RL 1985 Effects of a surfactant-associated protein and calcium ions on the structure and surface activity of lung surfactant lipids. Biochem J 24:184-190

9. Rannels SR, Gallaher KJ, Wallin R, Rannels DE 1987 Vitamin K-dependent carboxylation of pulmonary surfactant-associated proteins. Proc Natl Acad Sci USA 84:5952-5956

10. Friedman PA, Przysiecki CT 1987 Vitamin K-dependent carboxylation. Int J Biochem 19:1-7

11. Katyal SL, Singh G 1983 An enzyme linked immunoassay or surfactant apoprotein: its application to the study of fetal lung development in the rat. Pediatr Res 17:439-443

12. Bourbon JR, Farrell PM, Doucet E, Brown DJ, Valenza C 1987 Biochemical maturation of fetal rat lung: a comprehensive study including surfactant determination. Biol Neonate 52:48-60

13. Gross I, Dynia DW, Wilson CM, Ingleson LD, Gewolb IH, Rooney SA 1984 Glucocorticoid-thyroid hormone interactions in fetal rat lung. Pediatr Res 18:191-196

14. Ballard PL, Hawgood S, Liley H, Wellenstein G, Gonzales LW, Benson B. Cardell B, White RT 1986 Regulation of pulmonary surfactant apoprotein SP28-36 gene in fetal human lung. Proc Natl Acad Sci USA 83:9527-9531

15. Whitsett JA, Weaver TE, Lieberman MA, Clark JC, Daugherty C 1986 
Differential effects of epidermal growth factor and transforming growth factor $\beta$ on synthesis of $\mathrm{Mr}=35,000$ surfactant-associated protein in fetal lung. J Biol Chem 262:7908-7913

16. Bell RG 1980 Vitamin K-dependent carboxylation of glutamic acid residues to gamma-carboxyglutamic acid in lung microsomes. Arch Biochem Biophys 203:58-64

17. Fahey JL 1967 Chromatographic separation of immunoglobulins. Methods Immunol Immunochem 1:321-329

18. Peterson GL 1977 A simplification of the protein assay method of Lowry et al which is more generally applicable. Anal Biochem 83:346-356

19. Sosenko IRS, Frank L 1987 Thyroid hormone depresses antioxidant enzyme maturation in fetal rat lung. Am J Physiol 253:R592-R598
20. Wallin R, Rannels SR 1988 Identification of vitamin K-dependent carboxylase activity in lung type II cells but not in lung macrophages. Biochem $\mathrm{J} 250: 557$ 563

21. Price PA, Baukol AS 1981 1,25 Dihydroxyvitamin $D_{3}$ increases serum levels of the vitamin K-dependent bone protein. Biochem Biophys Res Commun 99:928-935

22. Karl PL, Friedman PA 1983 Effects of parathyroid hormone and vitamin D on the renal vitamin K-dependent carboxylating system. $J$ Biol Chem 258:12783-12786

23. Floros J, Phelps DS, Karembanas S, Taeusch HW 1986 Primary translation products, biosynthesis, and tissue specificity of the major surfactant protein in rat. $J$ Biol Chem 262:828-831 